\title{
SOME NEW RESULTS RELATED TO A CLASS OF GENERALIZED HURWITZ ZETA FUNCTION
}

\author{
Min-JiE LUO AND R. K. RAINA
}

\begin{abstract}
In this paper, we establish some new results associated with a class of functions (related to Hurwitz-Lerch zeta function) defined and introduced by Raina and Chhajed in [Acta Math. Univ. Comenianae, 73 (2004), 89-100]. Among the results obtained are the series representation, generating function relationship and their corresponding multidimensional extensions. Some reduced cases of our results are also discussed.
\end{abstract}

Mathematics subject classification (2010): 33C65, 33C90.

Keywords and phrases: Hurwitz-Lerch zeta function, series representation, $H$-function, generating function, multidimensional analogues.

Acknowledgement. The authors express their sincerest thanks to the referee for some valuable suggestions.

\section{REFERENCES}

[1] T. Amdeberhan, O. Espinosa, I. Gonzalez, M. Harrison, V. H. Moll and A. Straub, Ramanujan's Master Theorem, Ramanujan J. 29 (2012), 103-120.

[2] I. GonZalez and V. Moll, Definite integrals by the method of brackets. Part 1. Adv. Appl. Math., 45 (2010), 50-73.

[3] S. P. GoYAl AND R. K. LADDHA, On the generalized Riemann zeta function and the generalized Lambert transform, Ganita Sandesh, 11 (1997), 99-108.

[4] A. A. Kilbas And M. SAIGO, H-Transorms: Theory and Applications, Chapman \& Hall/CRC, Boca Raton/London/New York/Washington, D.C., 2004.

[5] S.-D. Lin And H. M. SRIVAstava, Some Families of the Hurwitz-Lerch zeta functions and associated fractional derivative and other integral representations, Appl. Math. Comput. 154 (2004), 725-733.

[6] A. M. Mathai, R. K. Saxena, And H. J. Haubold, The $H$-function: Theory and applications, Springer, New York, 2010.

[7] R. K. RAINA AND P. K. CHHAJED, Certain results involving a class of functions associated with the Hurwitz Zeta function, Acta Math. Univ. Comenianae, 73 (2004), 89-100.

[8] R. K. RAINA AND T. S. NAHAR, A note on certain class of functions related to Hurwitz zeta function and Lambert transform, Tamkang J. Math. 31 (2000), 49-56.

[9] A. L. Soubhia, R. Figueiredo Camargo, E. Capelas de Oliveira and J. JR. Vaz, Theorems for series in three-parameter Mittag-Leffler functions. Frac. Cal. Appl. Anal. 13 (2010), 9-20.

[10] H. M. SRIVASTAVA, A new family of the $\lambda$-generalized Hurwitz-Lerch zeta functions with applications, Appl. Math. Inform. Sci. 8 (2014), 1485-1500.

[11] H. M. SRIVAStava AND J. ChOI, Zeta and q-Zeta Functions and Associated Series and Integrals, Elsevier Science Publishers, Amsterdam, London and New York, 2012.

[12] H. M. SRivastava, K. C. Gupta, And S. P. Goyal, The H-Functions of One and Two Variables with Applications, South Asian Publishers, New Delhi and Madras, 1982. 
[13] H. M. SRivastava, M.-J. LuO AND R. K. Raina, New results involving a class of generalized Hurwitz-Lerch zeta functions and their applications, Turkish J. Anal. Number Theory 1 (2013), 2635.

[14] H. M. SRivastava And H. L. Manocha, A Treatise on Generating Functions (569 pp.). A Halsted Press Book (Ellis Horwood Limited, Chichester), John Wiley and Sons, New York, Chichester, Brisbane, and Toronto, 1984. 